\title{
Pathogenesis of aphthoid ulcers in Crohn's disease: correlative findings by magnifying colonoscopy, electron microscopy, and immunohistochemistry
}

\section{Division of \\ Gastroenterology, Department of Medicine, Kawasaki Medical School, Kurashiki, Japan Y Fujimura R Kamoi M Iida}

Correspondence to: Dr Y Fujimura, Division of Gastroenterology, Department of Medicine, Kawasaki Medical School, 577 Matsushima, Kurashiki, 701-01, Japan.

Accepted for publication 9 November 1995

Y Fujimura, R Kamoi, M Iida

\begin{abstract}
Background-The mechanism of ulceration in Crohn's disease remains unknown. Aims-To clarify the role of the follicle associated epithelium (FAE) of colonic lymphoid nodules in the formation of ulcers in Crohn's disease.

Methods-After identification of colonic lymphoid nodules and aphthoid lesions by magnifying colonoscopy, 76 biopsy specimens were obtained from 10 patients with Crohn's disease and three patients with colonic lymphoid hyperplasia. This study correlated magnifying colonoscopic, electron microscopic, and immunohistochemical findings of biopsy specimens.
\end{abstract}

Results-In Crohn's disease, scanning electron microscopy of lymphoid nodules surrounded by a red halo without visible erosions by magnifying colonoscopy, showed surface erosions 150-200 $\mu \mathrm{m}$ in size. These lymphoid nodules with red halos had small erosions either light microscopically or electron microscopically in 18 of 21 specimens $(86 \%)$. Correlation of scanning and transmission electron microscopy showed residues of FAE including $M$ cells at the edges of the erosions. In immunohistochemical studies, HLA-DR antigen was limited to $M$ cells of FAE in the patients with lymphoid hyperplasia without inflammatory bowel disease. In Crohn's disease patients in remission, however, HLA-DR antigen was strongly expressed over the entire FAE of lymphoid nodules with a red halo endoscopically, while the expression was weak and irregular in the mucosa surrounding the lymphoid nodules. HLA-DR was strongly expressed in the entire inflamed colonic mucosa in the active stage.

Conclusion-The red halo appearance surrounding lymphoid follicles seems to precede visible aphthoid ulcers and suggests that ulcerations in Crohn's disease originate from FAE, possibly related to its physiological role as a portal of entry for potentially pathogenic agents.

(Gut 1996; 38: 724-732)

Keywords: aphthoid ulcer, $\mathbf{M}$ cell, magnifying colonoscopy, electron microscopy, immunohistochemistry, Crohn's disease.
Crohn's disease is a chronic inflammatory disease with a pathogenesis that is still unknown, although granuloma formation and predilection for the terminal ileum, similar to intestinal tuberculosis, has suggested a mycobacterial origin. Colonic lymphoid hyperplasia, which is occasionally recognised in patients with inflammatory bowel disease, ${ }^{1}$ is also found in sarcoidosis, ${ }^{2}$ lower gastrointestinal bleeding, ${ }^{3}$ dysgammaglobulinaemia and hypogammaglobulinaemia, ${ }^{4}$ and has also been considered to be a normal variant, when not associated with other histological abnormalities. ${ }^{5}$ Crohn's disease has inevitably been present for a considerable period of time before the development of symptoms that bring patients to the attention of physicians. As Crohn's disease is a systemic condition, it may be erroneous to conclude that the sequence of development of lesions in areas of intestine without prior macroscopic involvement reflects disease pathogenesis.

Although Lockhart-Mummery and Morson ${ }^{6} 7$ reported that an early microscopic change in Crohn's disease was ulceration of lymphoid follicles and Peyer's patches in the terminal ileum, subsequent studies have concluded that the earliest pathological lesion of Crohn's disease is the granuloma, which can be found within the mucosa despite entirely normal overlying epithelium..$^{89}$ Aphthoid ulcers in the small and large intestines are endoscopically identified in areas without other macroscopic lesions in Crohn's disease. They are not specific as they also occur in various types of infectious enterocolitis ${ }^{10-14}$ and in intestinal Behçet's disease, ${ }^{15}$ yet in longterm follow up studies of aphthoid ulcers in Crohn's disease, there have been reports of the advance of these ulcers into longitudinal ulcers representing typical lesions of Crohn's disease. ${ }^{16}$ Makiyama et $a l^{8}$ reported that examination using a magnifying colonoscope after the application of $0.2 \%$ methylene blue showed a characteristic 'worm-eaten' appearance of the rectum in Crohn's disease patients regardless of the activity of the disease. There has, however, been no correlation of findings of these minute lesions by magnifying colonoscopy with light microscopy, electron microscopy, and immunohistochemistry. In this paper, we compared lesions seen by magnifying colonoscopy of lymphoid follicles in patients with Crohn's disease or with lymphoid hyperplasia using these three morphological approaches. 
TABLE I Clinical information of patients and site and number of specimens obtained by colonoscopic biopsy

\begin{tabular}{|c|c|c|c|c|c|c|c|c|c|c|c|c|}
\hline \multirow[b]{2}{*}{ Case } & \multirow[b]{2}{*}{ Age } & \multirow[b]{2}{*}{$\operatorname{Sex}$} & \multirow{2}{*}{$\begin{array}{l}\text { Clinical diagnosis } \\
\text { (extent of CD) }\end{array}$} & \multirow{2}{*}{$\begin{array}{l}\text { Activity } \\
\text { of } C D\end{array}$} & \multirow{2}{*}{$\begin{array}{l}\text { Endoscopic appearance } \\
\text { of colonic } \\
\text { lymphoid nodules }\end{array}$} & \multicolumn{7}{|c|}{ Site and number of colonoscopic biopsy specimens } \\
\hline & & & & & & $C$ & $A$ & $T$ & $D$ & $s$ & $R$ & Total \\
\hline 1 & 19 & $\mathbf{M}$ & CD (ileocolitis) & Active & $\mathbf{A U}, \mathbf{R H}(+)$ & 2 & 2 & 0 & 0 & 2 & 3 & 9 \\
\hline 2 & 60 & $\mathbf{M}$ & CD (ileitis) & Remission & $\mathrm{LH}$ & 2 & 4 & 0 & 0 & 0 & 2 & 8 \\
\hline 3 & 23 & $\mathbf{F}$ & CD (ileitis) & Remission & $\mathrm{LH}$ & 2 & 0 & 0 & 0 & 0 & 2 & 4 \\
\hline 4 & 23 & $\mathbf{F}$ & CD (colitis) & Active & $\overline{A U}, \mathbf{R H}(+)$ & 0 & 0 & 4 & 0 & 3 & 0 & 7 \\
\hline 5 & 14 & $\mathbf{M}$ & CD (ileitis) & Active & $\mathrm{AU}, \mathrm{RH}(+)$ & 1 & 1 & 1 & 1 & 0 & 3 & 7 \\
\hline 6 & 12 & $\mathbf{M}$ & CD (ileocolitis) & Active & AU & 1 & 2 & 0 & 0 & 2 & 3 & 8 \\
\hline 7 & 26 & $\mathbf{M}$ & CD (ileocolitis) & Active & $\mathrm{AU}, \mathbf{R H}(+)$ & 0 & 0 & 0 & 0 & 2 & 2 & 4 \\
\hline 8 & 25 & $\mathbf{M}$ & CD (colitis) & Remission & $\mathrm{AU}, \mathrm{RH}(+)$ & 0 & 0 & 0 & 1 & 3 & 1 & 5 \\
\hline 9 & 18 & $\mathbf{F}$ & CD (colitis) & Remission & $\mathrm{LH}$ & 0 & 0 & 0 & 0 & 2 & 1 & 3 \\
\hline \multirow{5}{*}{$\begin{array}{l}10 \\
11 \\
12 \\
13\end{array}$} & 25 & $\mathbf{M}$ & CD (ileitis) & Active & LH & 0 & 0 & 0 & 0 & 1 & 3 & 4 \\
\hline & 57 & $\mathrm{~F}$ & Lower GI bleeding & NA & LH & 1 & 1 & 0 & 0 & 2 & 2 & 6 \\
\hline & 76 & $\mathbf{M}$ & Lower GI bleeding & NA & LH & 0 & 3 & 0 & 0 & 0 & 2 & 5 \\
\hline & 42 & $\mathbf{F}$ & Radiation proctitis & NA & LH & 1 & 2 & 3 & 0 & 0 & 0 & 6 \\
\hline & & & & & Total & 10 & 15 & 8 & 2 & 17 & 24 & 76 \\
\hline
\end{tabular}

CD: Crohn's disease, AU: aphthoid ulcers, $\mathrm{RH}(+)$ : red halo appearance, $\mathrm{LH}$ : lymphoid hyperplasia, C: caecum, A: ascending colon. T: transverse colon, D: descending colon, $S$ : sigmoid colon, $R$ : rectum. NA= not applicable, GI= gastrointestinal.

\section{Methods}

\section{Patients}

Biopsy specimens were obtained endoscopically from aphthoid lesions and enlarged lymphoid nodules of the colorectal mucosa in 10 patients with Crohn's disease and three patients with lymphoid hyperplasia associated with non-inflammatory bowel disease. All of the Crohn's disease patients showed characteristic findings for Crohn's disease affecting the ileum or colon. The diagnosis has been previously established by clinical, radiological, and pathological criteria. The mean age of the Crohn's disease patients was 24 years (12-60) and that of the non-inflammatory bowel disease patients with colonic lymphoid hyperplasia was 58 years (42-76). Table I summarises the detailed background and endoscopic findings of the patients studied. All patients gave informed consent.

\section{Colonoscopic biopsies}

After the usual premedication, a colonoscopic examination was performed using a magnifying videocolonoscope (Olympus CF-200Z). After routine observation, $0.2 \%$ indigo carmine solution was directly sprayed on the mucosal surface of the colon through a Teflon tube inserted through the colonoscope. Then, magnifying colonoscopy was performed with $50 \times$ to $100 \times$ magnification. A total of 76 colonoscopic biopsy specimens were obtained from the caecum, ascending, transverse, and descending colon and the rectosigmoid region (Table I). The biopsy was done using standard type forceps (Olympus), and the size of the specimens obtained was approximately $3 \mathrm{~mm}$. All specimens were divided into three groups for light microscopic, electronic microscopic, and immunohistochemical examination.

TABLE II Classification of magnifying colonoscopy in aphthoid lesions

\begin{tabular}{lllllll}
\hline & \multicolumn{2}{l}{ Findings of magnifying colonoscopy } & & \multicolumn{2}{l}{ Findings of SEM } \\
\cline { 2 - 3 } \cline { 5 - 6 } Classification & Erosions & Red halo appearance & & Erosions & FAE \\
\hline Group I & $(-)$ & $(-)$ & $(+)$ & $(+)$ or $(-)$ & $(+)$ & $(-)$ or $(+)$ partially \\
Group II & $(-)$ & $(+)$ & & & $(+)$ & $(-)$
\end{tabular}

SEM: scanning electron microscopy, FAE: follicle associated epithelium.
Processing for light and electron microscopy

All biopsy specimens were rinsed with a physiological saline solution and fixed in $2.5 \%$ glutaraldehyde at $4^{\circ} \mathrm{C}$ for two hours. Light and electron microscopic observations were preceded by examination using a dissecting microscope. Scanning electron microscopic samples were postfixed in phosphate buffered $1 \%$ osmium tetroxide ( $\mathrm{pH} 7 \cdot 4$ ) for two hours, in $1 \%$ tannic acid overnight to improve the quality of the image, and again in $1 \%$ osmium tetroxide for one hour before dehydration through a graded ethanol series. After drying in a critical point dryer, specimens were coated with platinum-palladium and observed with a Hitachi S-570 scanning electron microscope. After scanning electron microscopy (SEM), the samples were removed from SEM sample strands, replaced into $99.5 \%$ ethanol, transferred to propylene oxide, and embedded in epoxy resin. Ultrathin sections were cut with glass knives using a Porter-Blum MT2-B ultramicrotome and stained with toluidine blue. When an erosion on the surface of a lymphoid follicle was seen, ultrathin sections were cut with diamond knives, subsequently stained with uranyl acetate and lead citrate, and examined with a Hitachi $\mathrm{H}-500$ transmission electron microscope.

\section{Processing for immunohistochemistry}

Biopsy specimens were immediately fixed in a periodate-lysine-2\% paraformaldehyde (PLP) solution for six hours at $4^{\circ} \mathrm{C}$, rinsed in a 0.01 $\mathbf{M}$ phosphate buffered saline series ( $\mathrm{pH} 7 \cdot 6$ ) containing graded concentrations of sucrose, and embedded in OCT compound (Miles Scientific, Elkhart, USA). They were then sectioned at $7 \mu \mathrm{m}$ by a cryostat, mounted on poly-L-lysine coated glass slides, and air dried at room temperature for three hours.

Sections were processed for examination of HLA-DR antigen using an avidin-biotin-peroxidase complex method. After the specimens were rinsed with $0.01 \mathrm{M}$ phosphate buffered saline, they were treated with $0.3 \%$ hydrogen peroxide in methanol for 10 minutes to inactivate endogenous peroxidase. The samples were then immersed in $10 \%$ normal horse serum for 30 minutes to block any non-specific reaction. After each of the above incubations, 
specimens were rinsed in $0.01 \mathrm{M}$ phosphate buffered saline, incubated with mouse monoclonal antihuman HLA-DR antibody (DAKO Japan, Tokyo, Japan), diluted 1:100 in 0.01 M phosphate buffered saline for 12 hours in moist chambers at $4^{\circ} \mathrm{C}$, and biotinylated with horse antimouse IgG (diluted 1:50 in $0.01 \mathrm{M}$ phosphate buffered saline containing $2 \%$ horse serum, Vector Laboratories, Burlingame, CA) for three hours. The specimens were then rinsed for 30 minutes in $0.01 \mathrm{M}$ phosphate buffered saline at $4^{\circ} \mathrm{C}$ and incubated with the avidin-biotin complex or the ABC reagent (a mixture of avidin $\mathrm{DH}$ solution and biotinylated enzyme, each diluted 1:50 with 0.01 $\mathrm{M}$ phosphate buffered saline). The horse serum, biotinylated antimouse IgG, and ABC complex are reagents in the Vectastain Elite ABC kit Vectastain; Vector Laboratories, Burlingame, CA). The incubated specimens were rinsed in $0.01 \%$ phosphate buffered saline for 10 minutes, and then fixed in $1 \%$ glutaraldehyde in $0.01 \mathrm{M}$ phosphate buffered saline. Then they were rinsed carefully six times in $0.01 \mathrm{M}$ phosphate buffered saline for five minutes.

For light microscopy, the samples were reacted with $0.02 \% 3,3^{\prime}$-diaminobenzidine tetrahydrochloride (DAB) diluted in $0.05 \mathrm{M}$ TRIS buffer, pH $7 \cdot 6$, for 30 minutes at room temperature, and subsequently in a $0.02 \%$ DAB solution containing $10 \mathrm{mM}$ hydrogen peroxide and $10 \mathrm{mM}$ sodium azide for five minutes.

For immunoelectron microscopy, specimens were treated as described above and then postfixed in $2 \%$ osmium tetroxide in phosphate buffered saline for one hour. They were then dehydrated in graded ethanol solutions, embedded in epoxy resin, and allowed to stand for three days for polymerisation. Ultrathin sections were cut with an MT2-B Porter-Blum ultramicrotome and examined in a Hitachi H-500 transmission electron microscope. For negative controls, non-immune mouse serum, mouse IgG1, and phosphate buffered saline were used in place of the first antibody.

\section{Results}

Correlative findings between magnifying videocolonoscopy and SEM in lymphoid nodules, lesions with a red halo appearance, and aphthoid lesions in Crohn's disease

Aphthoid lesions were endoscopically classified into three groups (groups I-III, Table II). Group I; round enlarged modules with a central depression from which mucosal patterns had disappeared but on the surface of which fine grooves were visible. The surface of these nodules was not associated with erosions under magnifying colonoscopy (Fig 1a). SEM of such lesions showed the surface of the apex in the lesion to have multiple grooves, to be slightly depressed, and to be covered by follicle associated epithelium including $M$ cells (Fig $1 b$ ). Group II; minute lesions associated with a small central depression and a red halo appearance by magnifying colonoscopy (Fig 1c). SEM and light microscopy of these lesions showed that the minute lesions associated with a red halo appearance and without visible erosion endoscopically included lesions associated with erosions detected by light microscopy or electron microscopy in 18 of 21 specimens (86\%) (Fig 1d). In areas of red halo appearance, congested and dilated capillaries in lamina propria surrounding lymphoid nodules were recognised histologically. Group III; small ulcers or erosions associated with round or irregular shaped white coat with visible dilated capillaries in the surrounding mucosa (Fig 1e). SEM of these lesions showed an irregular shaped erosion (Fig 1f).

\section{Correlative findings between SEM and} transmission electron microscopy (TEM) of lesions with a red halo appearance in Crohn's disease

Careful observation of the minute lesions associated with the appearance of red halos (group II, Table II) by SEM showed follicle associated epithelium (FAE) in a part of the mucosa surrounding the minute erosions (Fig $2 a, b)$. With observation of this part at higher magnifications, we noted $M$ cells with irregular and microridge-like microvilli on the surface (Fig 2c). Then, in light microscopic observation of the same sample (Fig 2a, b, c) that we had observed by SEM, we recognised that the erosion was located on the lymphoid follicle and FAE residues (Fig 2d). Under TEM of the same light microscopy sample, $M$ cells were seen in the FAE (Fig 2e).

Immunohistochemical studies of FAE in lymphoid hyperplasia of non-inflammatory bowel disease and of Crohn's disease

In the enlarged lymphoid nodules of the sigmoid colon with non-inflammatory bowel disease, magnifying colonoscopy showed white, round lymphoid nodules without red halo appearance (Fig 3a, b). Light microscopy of immunoperoxidase labelling of HLA-DR showed that the HLA-DR antigen was not expressed on normal mucosa surrounding lymphoid follicles (Fig 3c). However, parts of the FAE in the lymphoid follicles showed positive expression of HLA-DR (Fig 3c). Enlargement of the FAE showed expression of HLA-DR antigen by individual epithelial cells (Fig 3d). Immunoelectron microscopy of the section disclosed expression of HLA-DR antigen on the apical and basolateral plasma membranes and on the vacuole membrane in the cytoplasm of $M$ cells associated with lymphoid cells (Fig 3e) and 'microfold'-like microvilli on the surface of $M$ cells (Fig 3f). Adjacent absorptive cells showed only faint HLA-DR expression on the apical membrane (Fig 3e).

In the colonic lymphoid nodules with a red halo appearance seen endoscopically in the remission stage of Crohn's disease (Fig 4a, b), HLA-DR antigen was more strongly expressed over the entire FAE than in surrounding epithelium where reaction was weak and irregular (Fig 4c, d, e). In the active stage of 

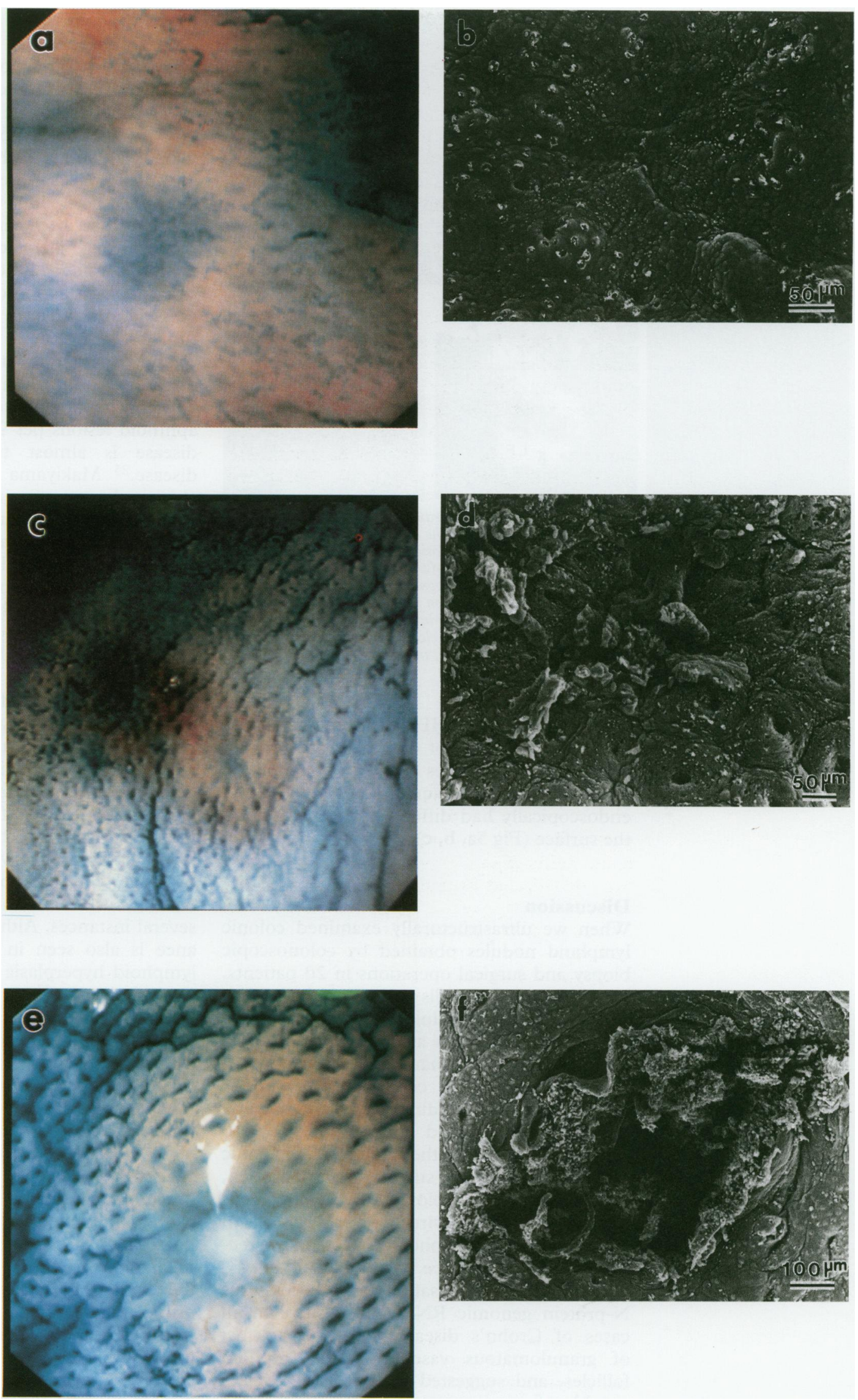

Figure 1: Aphthoid lesions of Crohn's disease could be divided into three groups. Group I. (a): Case 2. A magnifying colonoscopic picture of a white round lymphoid nodule with a central depression. (b): A scanning electron micrograph of the lymphoid nodule in Fig 1(a). Mucosal crypt patterns disappear on the nodule by a slight depressed surface but fine grooves are visible on the surface. Group II. (c): Case 1. A magnifying colonoscopic picture of a minute lesion with a red halo appearance. (d): A scanning electron micrograph of the lesion in Fig $1(\mathrm{c})$. There is a small erosion of 150-200 $\mu \mathrm{m}$ size on the surface. Group III. (e): Case 8. A magnifying colonoscopic picture of an aphthoid ulcer. $(f): A$ scanning electron micrograph of the lesion in Fig $1(e)$. An ulcer is clearly recognisable on the surface. 


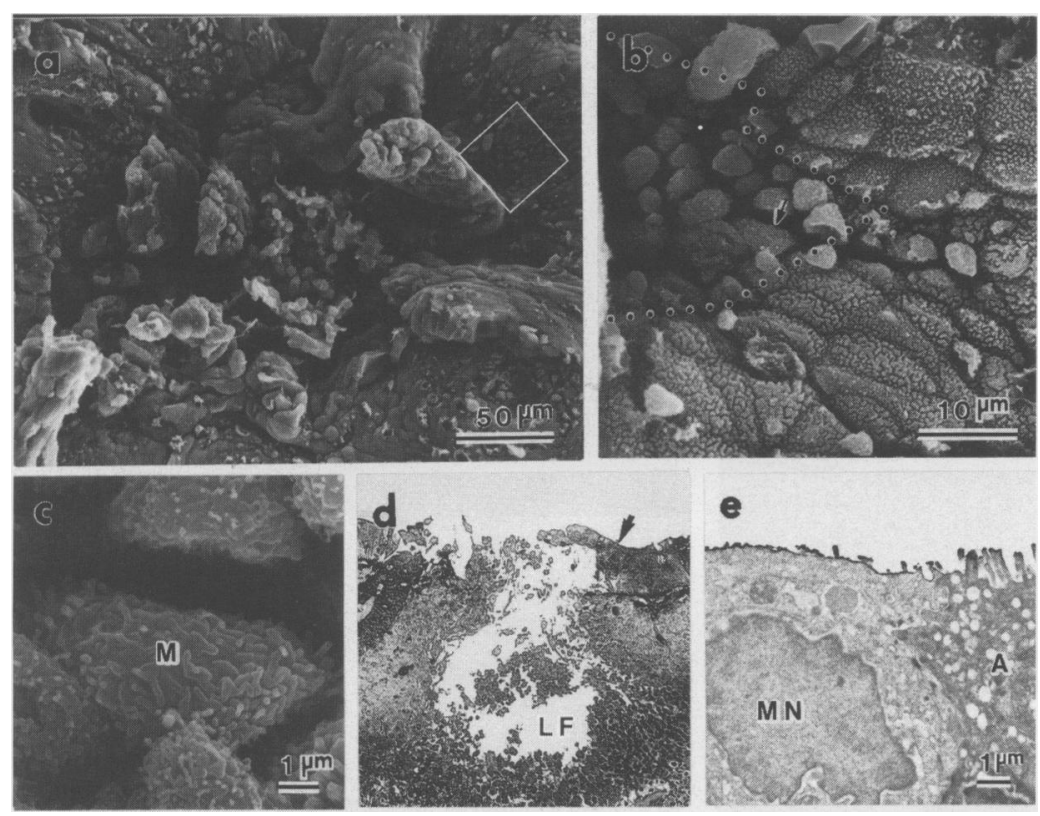

Figure 2: SEM and TEM of a lesion with a red halo appearance in Crohn's disease (Group II, Case 1). (a): Scanning electron micrograph of the ulcer in the centre of Fig 1(c). (b): Enlargement of the square at the margin of the erosion in Fig $2(a)$. The area surrounded by dots is a part of the FAE. (c): Enlargement of the cell shown by the arrow in Fig 2(b). An $M$ cell having microridge-like microvilli is recognised. $M ; M$ cell. (d): $A$ light micrograph of the same sample as shown in Fig $2(a)$. Erosion is found over a lymphoid follicle, and FAE (arrow) is recognised in a part of the interrupted epithelia over the lymphoid follicle. LF; lymphoid follicle. (e): A transmission electron micrograph of the FAE shows an $M$ cell with irregular and coarse 'microfolds'. MN; nucleus of an $M$ cell, $A$; an absorptive cell. ulcerative colitis (five of 196 cases), $77 \cdot 4 \%$ of Crohn's disease (24 of 31 cases), $80 \%$ of simple ulcer (four of five cases), $20 \%$ of campylobacter enterocolitis (two of 10 cases), $9.5 \%$ of haemorrhagic colitis (two of 21 cases), $40 \%$ of pseudomembraneous colitis (two of five cases), and in each of seven cases $100 \%$ of intestinal Behçet's disease, four cases of intestinal tuberculosis, four cases of amoebic colitis, and two cases of yersinia enterocolitis colonoscopically. ${ }^{24}$ In the differential diagnosis of aphthoid lesions, although Behçet's disease is associated with aphthoid lesions by definition, these lesions have no tendency toward longitudinal arrangement and have sharper and clearer margins compared with Crohn's disease. $^{2425}$ Furthermore, double contrast barium enema showed that the frequency of aphthoid lesions per 9 square $\mathrm{cm}$ in Behçet's disease is almost twice that in Crohn's disease. ${ }^{25}$ Makiyama et al described several abnormal patterns in aphthoid lesions of Crohn's disease, namely types $\mathrm{A}$ and $\mathrm{B}$, 'worm-eaten' lesions and 'white spot' lesions. ${ }^{8}$ In our study, we could classify three types of aphthoid lesions by magnifying videocolonoscopy using a dye spraying method with $0.2 \%$ indigocarmine solution. 'Worm-eaten' lesions reported by Makiyama et al, would seem to correspond to areas of erosion in group III in our classification.

After study by magnifying colonoscopy, as

Crohn's disease, HLA-DR antigen was expressed strongly not only over the FAE of the lymphoid nodules close to longitudinal ulcers, but also in the surrounding mucosa that endoscopically had diffuse strong redness on the surface (Fig 5a, b, c).

\section{Discussion}

When we ultrastructurally examined colonic lymphoid nodules obtained by colonoscopic biopsy and surgical operations in 20 patients, we showed that $M$ cells existed on the surface of these lymphoid nodules and that their basic structure was the same as that of $M$ cells in the Peyer's patches of humans. ${ }^{17}{ }^{18}$ Many morphological studies of $M$ cell uptake of various macromolecules including viruses and bacteria have been performed during the past 10 years. ${ }^{1920}$ Although the function of colonic lymphoid nodules is still not clearly known, Owen et al showed colonic and rectal $M$ cells and the uptake of reovirus type 1 by $M$ cells in the epithelium of lymphoid nodules in the rectum and colon of mice. ${ }^{21} 22$ Wakefield et al ${ }^{23}$ reported that hybridisation for measles virus $\mathrm{N}$-protein genomic RNA was positive in all cases of Crohn's disease, localising to foci of granulomatous vasculitis and lymphoid follicles, and suggested that measles virus is capable of causing persistent infection of the intestine and that Crohn's disease may be caused by a granulomatous vasculitis in response to this virus. If the pathogenesis of Crohn's disease entails infection by microorganisms or the entry of macromolecules, we speculate that $M$ cells may be their main entry to the intestinal mucosa.

Aphthoid lesions are recognised in $2 \cdot 6 \%$ of was done by Makiyama et al, we examined lymphoid follicles, minute lesions with a red halo appearance, and aphthoid lesions by SEM and TEM. SEM of lymphoid nodules in Crohn's disease, which had been found to have red halo appearance without apparent erosions several instances. Although a red halo appearance is also seen in ulcerative colitis ${ }^{26}$ and lymphoid hyperplasia of other aetiology than Crohn's disease, ${ }^{27}$ our findings suggest that the red halo appearance surrounding lymphoid follicles without erosions on the surface is an earlier sign of impending mucosal disruption in Crohn's disease than aphthoid ulcers.

Wakefield et $a l^{28}$ reported an occlusive fibrinoid lesion of the arteries supplying areas of the intestine affected by Crohn's disease and suggested that vascular damage precedes mucosal ulceration in Crohn's disease. Sankey et $a^{29}$ identified a sequence of superficial mucosal change occurring before the development of microulcers, including disruption of the capillary basement membrane with haemorrhage and trials of fibrinogen originating from ruptured capillaries and extending towards the surface epithelium. This 'summit' lesion was seen in the absence of local inflammatory changes. They suggested that capillary disruption precedes inflammation. Our data also indicate that this would be the earliest endoscopic appearance in the mucosa of Crohn's disease preceding mucosal erosions.

Granulomas or microgranulomas are found in $75 \%$ of biopsy specimens from the 'wormeaten' lesion compared with only $30 \%$ in adjacent normal mucosa. ${ }^{8}$ There is an absolute by magnifying colonoscopy, showed erosions on the surface of the lymphoid nodules in 

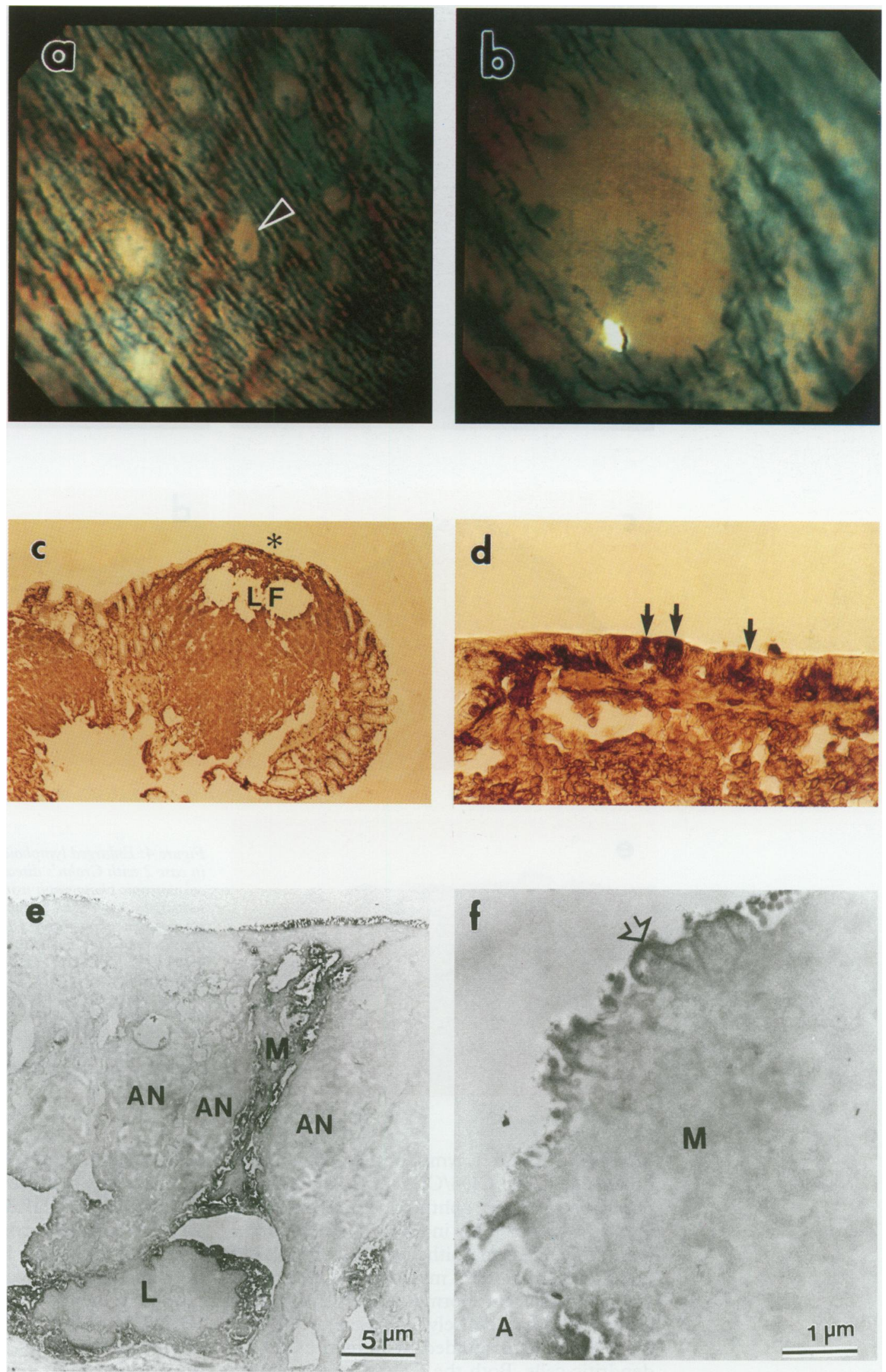

Figure 3: Enlarged lymphoid nodule of the sigmoid colon in case 11 with non-inflammatory bowel disease. (a): $A$ colonoscopic picture of enlarged lymphoid nodules. (b): A magnifying colonoscopic photograph of the lymphoid nodule shown by an arrowhead in Fig 3(a). (c): HLA-DR staining of the biopsy specimens obtained from the lymphoid nodule shown in Fig $3(b)(\times 30)$. (d): Enlargement of the FAE $\left.{ }^{*}\right)$ in the specimen shown in Fig $3(c)$. Three arrows show epithelial cells with $H L A-D R$ positive reaction $(\times 260)$. (e): Immunoelectron microscopy of the specimen in Fig $3(d)$ shows an $M$ cell expressing $H L A-D R$ antigen associated with a lymphoid cell. Note that $H L A-D R$ antigen is expressed on the apical and basolateral membranes and on the vacuole membrane in the cytoplasm of an $M$ cell. $M$; an $M$ cell, $A N$; nucleus of an absorptive cell. (D: An immunoelectron micrograph showing a parallel section of the apex of the $M$ cell seen in Fig $3(e)$. The apical membrane of the $M$ cell shows expression of $H L A-D R$ antigen. Open arrow; 'microfold'-like in Fig $3($ (e). The apical membrane of the $M$ cell
microvilli of the M cell, $A ;$ an absorptive cell. 

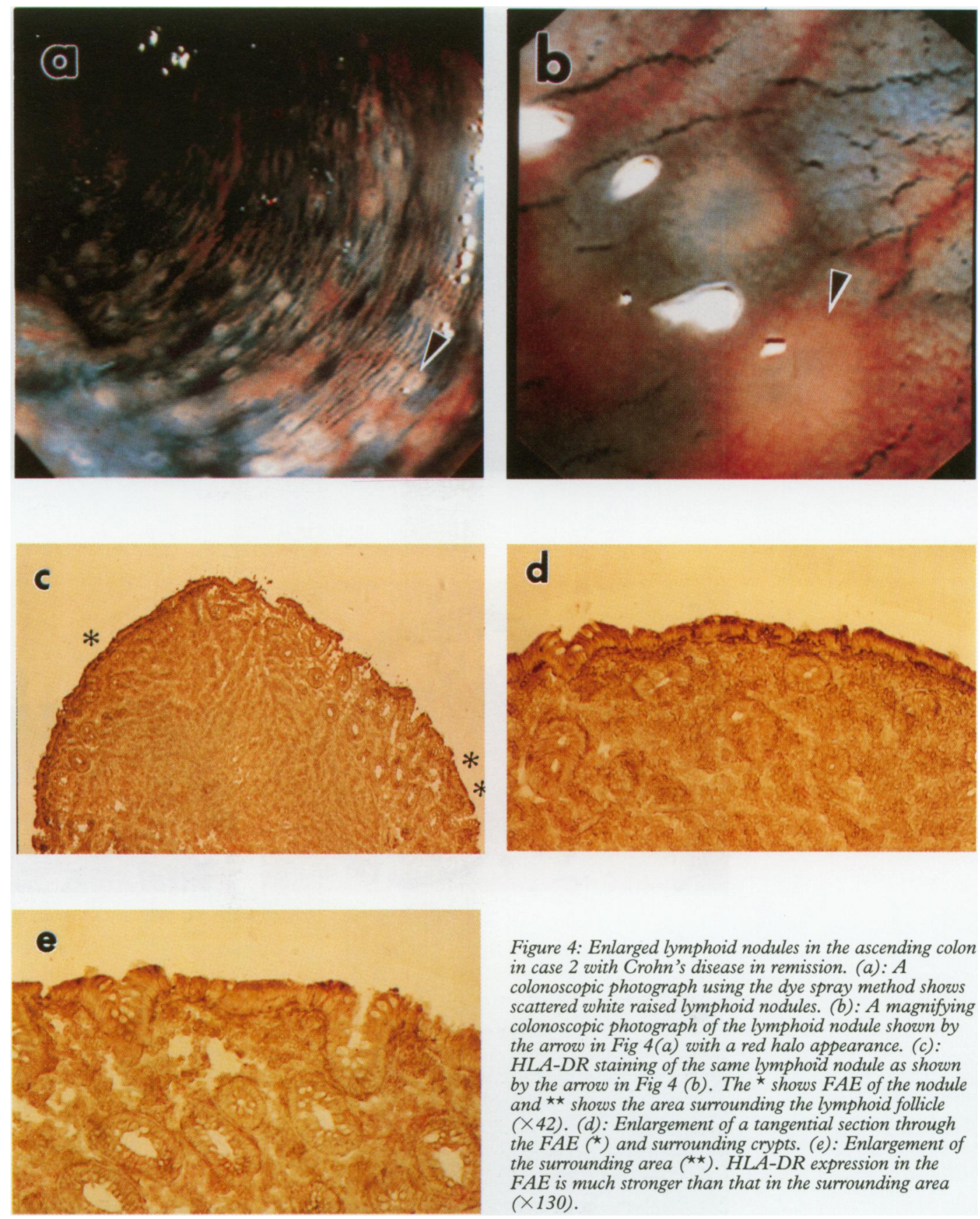

Figure 4: Enlarged lymphoid nodules in the ascending colon in case 2 with Crohn's disease in remission. (a): A colonoscopic photograph using the dye spray method shows scattered white raised lymphoid nodules. (b): A magnifying colonoscopic photograph of the lymphoid nodule shown by the arrow in Fig 4(a) with a red halo appearance. (c): $H L A-D R$ staining of the same lymphoid nodule as shown by the arrow in Fig 4 (b). The * shows FAE of the nodule and ${ }^{\star \star}$ shows the area surrounding the lymphoid follicle $(\times 42)$. (d): Enlargement of a tangential section through the FAE $\left(^{\star}\right)$ and surrounding crypts. (e): Enlargement of the surrounding area $\left(^{\star \star}\right)$. HLA-DR expression in the $F A E$ is much stronger than that in the surrounding area $(\times 130)$.

increase in B and T lymphocytes, but there is no change in the CD4/CD8 ratio in the $T$ cell population..$^{3031}$ In aphthoid lesions, there is also a distinct increase in $\mathrm{RFD9}^{+}$, a cell marker that is detected on epithelioid cells in sarcoid granuloma, and $3 \mathrm{G8}^{+}$macrophages compared with the adjacent normal area. ${ }^{31}$. Aphthoid lesions contain densely aggregated $\mathrm{CD}^{+} 8^{+}$ macrophages surrounded by numerous ID- ${ }^{+}$ dendritic cells. Both the $\mathrm{CD} 68^{+}$macrophages and ID- $1^{+}$dendritic cells express ICAM-1 and HLA-DR antigens. ${ }^{32}$ In contrast, a much lower density of both $\mathrm{CD}^{+} 8^{+}$macrophages and ID- $1^{+}$dendritic cells was found in the normal colonic mucosa and the inflamed mucosa of infectious colitis patients. ${ }^{32}$

Our study of HLA-DR expression suggests that abnormalities of immunological response may occur in the mucosa around the FAE of lymphoid follicles in Crohn's disease even before aphthoid ulcers are manifested. It has

been shown that HLA-DR antigens are required for antigen recognition by helper $T$ cells, and that HLA-DQ antigens are necessary for antigen recognition by suppressor $T$ cells. In addition, HLA-DP antigens have been shown to be necessary for antigen recognition by helper $T$ cells in cooperation with HLA-DR antigens. Although some data are available regarding the relation between M cells and MHC class II in Peyer's patches, there are none concerning that relation in colonic lymphoid nodules. We found that $M$ cells of enlarged lymphoid nodules of more than $3 \mathrm{~mm}$ in size were HLA-DR positive in three patients with colonic lymphoid hyperplasia caused by non-inflammatory bowel disease. There is still no consensus as to whether $M$ cells in Peyer's patches are HLADR positive or not. While some reports have found no expression of MHC class II on rat or human $M$ cells in Peyer's patches by light 

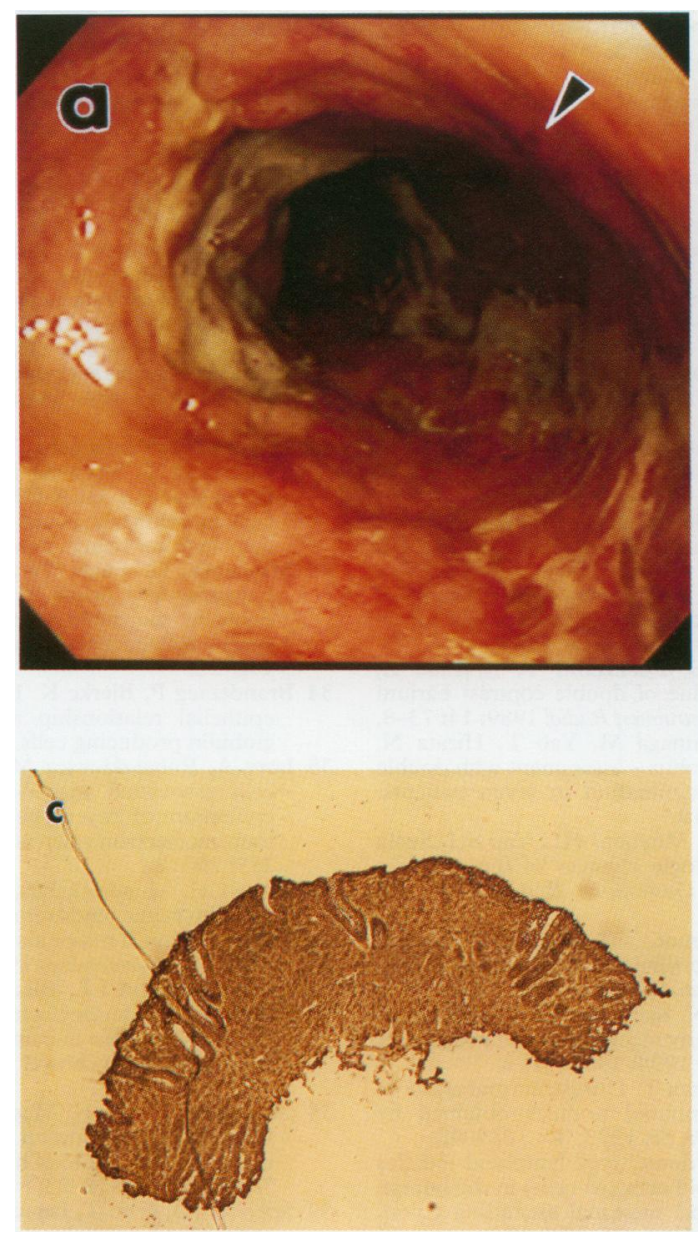

microscopic immunohistochemistry, ${ }^{33} 34$ two studies using immunoelectron microscopy found intense expression of Ia antigen on $M$ cells in rat Peyer's patches. ${ }^{35}{ }^{36}$ Furthermore, two other papers reported that $M$ cells in human Peyer's patches showed HLA-DR expression on their apical and basolateral membranes. ${ }^{37} 38$ Our data show that HLA-DR antigen is expressed on the apical and basolateral membranes of $M$ cells in patients with colonic lymphoid hyperplasia. Further study is necessary to discover if HLA-DR expression by $M$ cells is positive in normal sized or smaller lymphoid nodules.

HLA-DR antigens are physiologically expressed on the epithelium of the small intestine, ${ }^{33} 39$ but expression of HLA-DR antigens has not been seen on normal colonic epithelium. ${ }^{39-41}$ HLA-DR expression has been reported on the epithelium of lesions in diseases such as ulcerative colitis, ${ }^{41}$ Crohn's disease, ${ }^{42}$ non-inflammatory bowel disease colitis, ${ }^{43}$ colon polyps, ${ }^{44}$ and colorectal cancer. ${ }^{45}$ In the large intestine, Chiba et al $^{42}$ noted that, although the HLA-DR antigens are not expressed on the epithelium in macroscopically uninvolved areas in ulcerative colitis, ${ }^{41}$ they are expressed with a high frequency in macroscopically uninvolved areas in Crohn's disease. They also found that, when Crohn's disease was most active before treatment, HLA-DR antigens were always expressed in the large intestine, but when the disease had been suppressed after treatment, the antigens were not always expressed even in

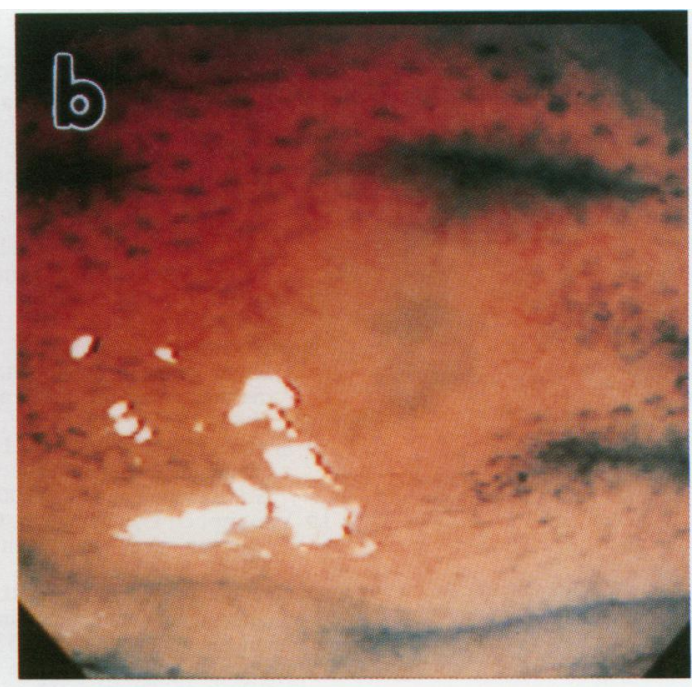

Figure 5: Lymphoid nodule of the transverse colon in case 4 with active Crohn's disease. (a): A colonoscopic photograph showing longitudinal ulcers in the upper left and lower right with cobblestone mucosa inferiorly. Arrowhead shows a lymphoid nodule near the longitudinal ulcer. (b): Magnifying colonoscopy shows the lymphoid nodule shown by the arrowhead in Fig 5(a). (c): HLA-DR staining of the lymphoid nodule in Fig 5(b) shows diffuse strong expression extending to the surrounding area $(\times 35)$.

macroscopically involved areas. ${ }^{42}$ Recently, they reported expression of HLA-DR antigens on the epithelium around the lymphoid follicles in Crohn's disease. ${ }^{46}$ However, the relation between HLA-DR expression and FAE including $M$ cells was not determined. Using light microscopy and immunoelectron microscopy, we found that HLA-DR antigens were more strongly expressed in FAE than in the surrounding mucosa of lymphoid nodules in the remission stage of Crohn's disease, and were strongly expressed in the entire mucosa including lymphoid nodules in the active stage of this disease. We speculate that, when lymphoid follicles are stimulated and enlarge because of the entry of certain antigens through $M$ cells, HLA-DR expression extends from the $M$ cells on enlarged lymphoid nodules throughout the FAE and to mucosa surrounding the lymphoid nodules.

In conclusion, our immunohistochemical and electron microscopic findings suggested that mucosal ulcerations in Crohn's disease originate from FAE and that this localisation may be a consequence of the known physiological function of these zones of entry for potentially pathogenic agents and for normally non-invasive enteric organism.

The authors wish to thank Dr R L Owen (Department of Medicine, University of California, San Francisco) for his advice. This study was supported by Project Research Grant no 6-605 from Kawasaki Medical School and by the ministry of 6-605 from Kawasaki Medical School and by the ministry of
education, science, and culture of the Japanese government. education, science, and culture of the Japanese government.
Part of this study was presented at the 8th international conPart of this study was presented at the 8th intern
gress of mucosal immunology (San Diego, 1995).

1 Kelvin FM, Oddson TA, Rice RP, Garbutt JT, Bradenham BP. Double contrast barium enema in Crohn's disease and ulcerative colitis. Am $\mathcal{f}$ Roentgenol 1978; 131: 207-13.

2 Ell SR, Frank PH. Spectrum of lymphoid hyperplasia: colonic manifestations of sarcoidosis, infectious mononucleosis and Crohn's disease. Gastrointest Radiol 1981; 6:

3 Kaplan B, Benson J, Rothstein F, Dahms B, Halpin T. Lymphonodular hyperplasia of the colon as a pathologic 
finding in children with lower gastrointestinal bleeding. f Pediatr Gastroenterol Nutr 1984; 3: 704-8.

4 de Smet AA, Turbergen DG, Martel W. Nodular lymphoid hyperplasia of the colon associated with dysgammaglobulinemia. Am ₹ Roentgenol 1976; 127: 515-7.

5 Burbige EJ, Sobky RZF. Endoscopic appearance of colonic lymphoid nodules: a normal variant Gastroenterology 1977; 72: 524-6.

6 Lockhart-Mummery HE, Morson BC. Crohn's disease (regional enteritis) of the large intestine and its distinction from ulcerative colitis. Gut 1960; 1: 87-105.

7 Morson BC. The earliest histological lesion of Crohn's disease. Proc $R$ Soc Med 1972; 65: 71-2.

8 Makiyama K, Bennett MK, Jewell DP. Endoscopic appearances of the rectal mucosa of patients with Crohn's disease visualized with a magnifying colonoscope. Gut 1984; 25: 337-40.

9 Wakefield AJ, Sankey EA, Hillon AP, Sawyer AM, More L, Sim $R$, et al. Granulomatous vasculitis in Crohn's disease. Gastroenterology 1990; 100: 1279-87.

10 Vantrappen G, Ponette A, Geboes K, Bertrand P. Yersinia enteritis and enterocolitis. Gastroenterology 1977; 72: 220-7.

11 Cau-Lacke DL, Finlay DBL. Radiological demonstration of colonic aphthoid ulcers in a patient with intestinal tuberculosis. Gut 1982; 24: 453-5.

12 Matsui $T$, Iida $M$, Tada S, Fuchigami T, Iwashita A, Sakamoto $F$, et al. The value of double contrast barium enema in amebic colitis. Gastrointest Radiol 1989; 14: 73-8.

13 Nakamura $S$, Iida $M$, Tominaga $M$, Yao $T$, Hirata $N$, Fujishima M. Salmonella colitis - assessment with double contrast barium enema examination in seven patients. Radiology 1992; 184: 537-40.

14 Tielbeek AV, Rosenbusch G, Muytjens HL, Yap SH, Strijk SP, Boetes C. Roentgenologic changes of the colon in Campylobacter infection. Gastrointest Radiol 1985; 10: 358-61.

15 Iida M, Kobayashi H, Matsumoto T, Okada M, Fuchigami $T$, Niizeki $H$, et al. Intestinal Behçet disease: serial
changes at radiography. Radiology 1993; 188: 65-9.

16 Hizawa K, Iida M, Kohrogi N, Kuroki F, Yao T, Sakamoto $\mathrm{K}$, et al. Crohn's disease: early recognition and progress of aphthous lesions. Radiology 1994; 190: 451-4.

17 Fujimura $Y$, Hosobe $M$, Kihara T. Ultrastructural study of $M$ cells from colonic lymphoid nodules obtained by colonoscopic biopsy. Dig Dis Sci 1992; 37: 1089-98.

18 Hosobe M. Distribution of 'dome' type lymphoid follicles and morphology of microfold cells ( $M$ cells) in the human Bauchin's valve, cecum and proximal ascending colon. Medical Electron Microscopy 1992; 26: 139-49.

19 Fujimura Y, Kihara T, Mine H. Membranous cells as a portal of Yersinia pseudotuberculosis entry into rabbit ileum. fournal of Clinical Electron Microscopy 1992; 25: 35-45.

Journal of Clinical Electron Microscopy 1992; 25: 35-45.
20 Kato T, Owen RL. Structure and function of intestinal mucosal epithelium. In: Ogra R, Mestecky J, Lamm M, Strober W, McGhee J, Bienenstock J, eds. Handbook of mucosal immunology. Orlando, FL: Academic Press, 1994: 11-26.

21 Owen RL, Piazza AJ, Ermak TH. Ultrastructural and cytoarchitectural features of lymphoreticular organs in the
colon and rectum of adult BALB/c mice. Am f Anat 1991; 190: $10-8$.

22 Owen RL, Bass DM, Piazza AJ. Colonic lymphoid patches - a portal of entry in mice for type 1 reovirus administered anally [Abstract]. Gastroenterology 1990; 98: A468.

23 Wakefield AJ, Pittilo RM, Sim R, Cosby SL, Stephenson JR, Dhillon AP, et al. Evidence of persistent measles virus infecDhillon AP, et al. Evidence of persistent measles virus in

24 Tada $M$, Fujita $K$, Itoh $Y$, Shibatoga M, Sugata N, Shimizu $\mathrm{S}$, et al. Endoscopic differential diagnosis of aphthoid lesions in the intestine. (In Japanese.) Stomach and Intestine 1993; 28: 411-8.

25 Iida M, Hizawa K, Aoyagi K, Matsumoto T, Fuchigami T, Sakurai $\mathrm{T}$, et al. Radiographic differential diagnosis of aphthoid lesions of the colon: focused on Crohn's disease with aphthoid lesions alone. (In Japanese.) Stomach and Intestine 1993; 28: 397-410.

26 Kimura M, Miki K, Ichinose M, Hoshino E, Sano J, Kawamura N, et al. A new endoscopic finding of inflammatory bowel disease (IBD) [Abstract]. Gastroenterology 1990; 98: A181.
27 Chiba $M$, Iizuka $M$, Ohtaka $M$, Kuwabara $T$, Masamune $\mathrm{O}$, Mukoujima $\mathrm{T}$, et al. Four cases of the red ring sign. Gastrointest Endosc 1992; 38: 728-30.

28 Wakefield AJ, Sawyer AM, Dhillon AP, Pittilo PM, Rowles PM, Lewis AAM. Pathogenesis of Crohn's disease: multifocal gastrointestinal infarction. Lancet 1989; ii: 1057-62.

29 Sankey EA, Dhillon AP, Anthony A, Wakefield AJ, Sim R, More L, et al. Early mucosal changes in Crohn's disease. More L, et al. Early muco

30 Selby WS, Janossy G, Bofill M, Jewell DP. Intestinal lymphocyte subpopulations in inflammatory bowel disease: phocyte subpopulations in inflammatory bowel disease:
an analysis by immunohistological and cell isolation techniques. Gut 1984; 25: 32-40.

31 Gionchetti P, Mahida YR, Petel S, Jewell DP. Macrophage and lymphocyte subpopulations in magnifying endoscopic lesions of Crohn's disease. Clin Exp Immunol 1988; 72: 373-6.

32 Morise $\mathrm{K}$, Yamaguchi $\mathrm{T}$, Kuroiwa A, Kanayama $\mathrm{K}$, Matsuura T, Shimoda M, et al. Expression of adhesion molecules and HLA-DR by macrophages and dendritic cells in aphthoid lesions of Crohn's disease: an immunocytochemical study. F Gastroenterol 1994; 29: 257-64.

33 Mayrhofer G, Pugh CW, Barclay AN. The distribution, ontogeny and origin in the rat of Ia-positive cells with dendritic morphology and of Ia antigen in epithelia, with dendritic morphology and of Ia antigen in epithelia, with special $\mathrm{r}$.

34 Brandtzaeg P, Bjerke K. Human Peyer's patches: lymphoepithelial relationship and characteristics of immunoglobulin producing cells. Immunol Invest 1989; 18: 29-45.

35 Jarry A, Robaszkiewicz $M$, Brousse N, Potet F. Immune cells associated with $M$ cells in the follicle-associated epithelium of Peyer's patches in the rat: an electron- and immunoelectron microscopic study. Cell Tissue Res 1989; 255: 293-8.

36 Allan $\mathrm{CH}$, Mendrick DL, Trier JS. Rat intestinal M cells contain acidic endosomal-lysosomal compartments and express class II major histocompatibility complex determinants. Gastroenterology 1993; 104: 698-708.

37 Hirata I, Austin LI, Blackwell WH, Weber JR, Dobbins WO III. Immunoelectron microscopic localization of HLA-DR antigen in control small intestine and colon and in inflammatory bowel disease. Dig Dis Sci 1986; 31: 1317-30.

38 Nagura H, Ohtani H, Masuda T, Kimura M, Nakamura S. HLA-DR expression on $M$ cells overlying Peyer's patches is a common feature of human small intestine. Acta Pathol fpn 1991; 41: 818-23.

39 Spencer JO, Finn T, Isaacson PG. Expression of HLA-DR antigens on epithelium associated with lymphoid tissue in the human gastrointestinal tract. Gut 1986; 27: in the

40 Selby WS, Janossy G, Mason DY, Jewell DP. Expression of HLA-DR antigens by colonic epithelium in inflammatory HLA-DR antigens by colonic epithelium in inflam

41 lizuka $\mathrm{M}$, Chiba $\mathrm{M}$, Ohta $\mathrm{H}$, Kodama $\mathrm{K}$, Igarashi $\mathrm{K}$, Arakawa $\mathrm{H}$, et al. Expression of HLA-DR antigens on colonic epithelium in ulcerative colitis. Gastroenterol $\jmath_{p n}$ 1987; 22: 571-7.

42 Chiba M, Iizuka M, Horie Y, Igarashi K, Masamune O. HLA-DR antigen expression in macroscopically uninvolved areas of intestinal epithelia in Crohn's disease. Gastroenterol fpn 1989; 24: 365-72.

43 Iizuka $M$, Chiba $M$, Horie Y, Masamune $O$, Ohta $H$. Lymphoid cell subsets in colonic mucosa and HLA-DR antigens on colonic epithelia in colitis excluding ulcerative colitis and Crohn's disease. Gastroenterol fpn 1990; 25: 700-7.

44 Horie Y, Chiba M, Iizuka M, Igarashi K, Masamune O. Colonic lymphoid cell subsets and epithelial HLA-DR antigens in familial polyposis coli. Gastroenterol fpn 1989; 24: 632-9.

45 Horie Y, Chiba M, Iizuka M, Masamune O. Class II (HLADR, -DP, and -DQ) antigens on intestinal epithelia in ulcerative colitis, Crohn's disease, colorectal cancer and normal small intestine. Gastroenterol fpn 1990; 25: 575-84.

46 Chiba $M$, Iizuka $M$, Horie $Y$, Ishii $N$, Masamune $O$. Expression of HLA-DR antigens on colonic epithelium around lymph follicles. An anomalous expression in around lymph follicles. An anomalous expre 